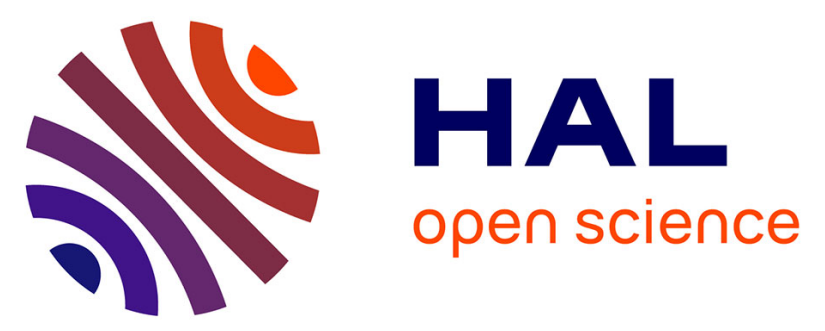

\title{
Vulnerability of permafrost carbon to global warming. Part I: model description and role of heat generated by organic matter decomposition
}

D. Khvorostyanov, Philippe Ciais, Gerhard Krinner, M. Heimann, S. A. Zimov

\section{- To cite this version:}

D. Khvorostyanov, Philippe Ciais, Gerhard Krinner, M. Heimann, S. A. Zimov. Vulnerability of permafrost carbon to global warming. Part I: model description and role of heat generated by organic matter decomposition. Tellus B - Chemical and Physical Meteorology, 2008, 60 (2), pp.250 à 264. 10.1111/j.1600-0889.2007.00333.x . insu-00378489

\section{HAL Id: insu-00378489 \\ https://hal-insu.archives-ouvertes.fr/insu-00378489}

Submitted on 29 Oct 2020

HAL is a multi-disciplinary open access archive for the deposit and dissemination of scientific research documents, whether they are published or not. The documents may come from teaching and research institutions in France or abroad, or from public or private research centers.
L'archive ouverte pluridisciplinaire $\mathbf{H A L}$, est destinée au dépôt et à la diffusion de documents scientifiques de niveau recherche, publiés ou non, émanant des établissements d'enseignement et de recherche français ou étrangers, des laboratoires publics ou privés. 


\title{
Vulnerability of permafrost carbon to global warming. Part I: model description and role of heat generated by organic matter decomposition
}

\author{
D. V. Khvorostyanov, G. Krinner, P. Ciais, M. Heimann \& S. A. Zimov
}

To cite this article: D. V. Khvorostyanov, G. Krinner, P. Ciais, M. Heimann \& S. A. Zimov (2008) Vulnerability of permafrost carbon to global warming. Part I: model description and role of heat generated by organic matter decomposition, Tellus B: Chemical and Physical Meteorology, 60:2, 250-264, DOI: 10.1111/j.1600-0889.2007.00333.x

To link to this article: https://doi.org/10.1111/j.1600-0889.2007.00333.x

\section{(c) 2008 The Author(s). Published by Taylor \& Francis.}

曲 Published online: 18 Jan 2017.

Submit your article to this journal 지

Џ Article views: 305

Q View related articles $₫$

7 Citing articles: 60 View citing articles $ぇ$ 


\title{
Vulnerability of permafrost carbon to global warming. Part I: model description and role of heat generated by organic matter decomposition
}

\author{
By D. V. KHVOROSTYANOV ${ }^{1,2,3 *}$, G. KRINNER ${ }^{2}$, P. CIAIS $^{1}$, M. HEIMANN ${ }^{4}$ \\ and S. A. ZIMOV ${ }^{5},{ }^{1}$ Laboratoire des Sciences du Climat et l'Environnement, Saclay, France; ${ }^{2}$ Laboratoire de \\ Glaciologie et Géophysique de l'Environnement, St Martin d'Heres, France; ${ }^{3}$ A. M. Obukhov Institute of Atmospheric \\ Physics RAS, Moscow, Russia; ${ }^{4}$ Max-Planck Institute of Biogeochemistry, Jena, Germany; ${ }^{5}$ Northeast Science Station, \\ Cherskii, Russia
}

(Manuscript received 3 November 2005; in final form 8 November 2007)

\begin{abstract}
We constructed a new model to study the sensitivity of permafrost carbon stocks to future climate warming. The one-dimensional model solves an equation for diffusion of heat penetrating from the overlying atmosphere and takes into account additional in situ heat production by active soil microorganisms. Decomposition of frozen soil organic matter and produced $\mathrm{CO}_{2}$ and methane fluxes result from an interplay of soil heat conduction and phase transitions, respiration, methanogenesis and methanotrophy processes. Respiration and methanotrophy consume soil oxygen and thus can only develop in an aerated top-soil column. In contrast, methanogenesis is not limited by oxygen and can be sustained within the deep soil, releasing sufficient heat to further thaw in depth the frozen carbon-rich soil organic matter. Heat production that accompanies decomposition and methanotrophy can be an essential process providing positive feedback to atmospheric warming through self-sustaining transformation of initially frozen soil carbon into $\mathrm{CO}_{2}$ and $\mathrm{CH}_{4}$. This supplementary heat becomes crucial, however, only under certain climate conditions. Oxygen limitation to soil respiration slows down the process, so that the mean flux of carbon released during the phase of intense decomposition is more than two times less than without oxygen limitation. Taking into account methanogenesis increases the mean carbon flux by $20 \%$. Part II of this study deals with mobilization of frozen carbon stock in transient climate change scenarios with more elaborated methane module, which makes it possible to consider more general cases with various site configurations. Part I (this manuscript) studies mobilization of $400 \mathrm{GtC}$ carbon stock of the Yedoma in response to a stepwise rapid warming focusing on the role of supplementary heat that is released to the soil during decomposition of organic matter.
\end{abstract}

\section{Introduction}

One of the consequences of the global warming is mobilization of carbon in the so-called vulnerable terrestrial pools, which can act as a positive feedback on the global carbon cycle and accelerate the rise of $\mathrm{CO}_{2}$ (Cox et al., 2000; Dufresne et al., 2002). Although there are large uncertainties on the magnitude of these carbon-climate feedbacks, and on the underlying processes, several studies pointed out that the future terrestrial carbon sinks could be strongly diminished in response to climate change. For instance, Cramer et al. (2001), Cao and Woodward (1998) using dynamic vegetation models simulated $21-43 \%$ less uptake

\footnotetext{
*Corresponding author.

e-mail: Dimitry.Khvorostiyanov@1sce.ipsl.fr

DOI: $10.1111 /$ j.1600-0889.2007.00333.x
}

of $\mathrm{CO}_{2}$ by the vegetation under the climate change simulated by coupled general circulation models with IS92a scenario of atmospheric $\mathrm{CO}_{2}$ concentration growth. Coupled global climatecarbon cycle simulations (Cox et al., 2000; Dufresne et al., 2002) concluded that tropical ecosystems may absorb less $\mathrm{CO}_{2}$ in the future, with even (in the study Cox et al., 2000) a 'dyeback' of tropical forest caused by drier conditions, yielding to dramatic losses of tropical soil carbon to the atmosphere. In all these studies, a common factor decreasing land storage of carbon is an anticipated increase in heterotrophic respiration in response to warming (Fang et al., 2005; Knorr et al., 2005).

High latitudes have long been recognized as a major sensitive 'hot spot' of the climate system and of the global carbon cycle (Serreze et al., 2000). There is ample evidence for recent changes in Northern high-latitude environments (Serreze et al., 2000). The average annual temperature in the Arctic has increased by 
about $1{ }^{\circ} \mathrm{C}$ over the last century, a rate that is approximately double that of global average temperatures (IPCC, 1998). Snow cover extent has decreased by about $10 \%$ since 1966 (IPCC, 2001). It is widely agreed that such climate changes will continue during the next century, resulting in large warming rates, in changes in moisture regime and in surface hydrology. One of the main consequences of the anticipated climate change at high latitudes is a significant northward shift of the permafrost regions (Anisimov and Nelson, 1997). Permafrost warming has been reported in Russia, China, Alaska and western Canada (Osterkamp et al., 1998). In the course of the future warming of northern high latitudes, permafrost will continue to retreat (IPCC, 2001). For instance, a 30-40\% increase in the active layer thickness at most of the permafrost area in the Northern Hemisphere is predicted by Stendel and Christensen (2002) for the IPCC SRES A2 climate scenario. Their model, however, did not include soil freeze-thaw processes. Lawrence and Slater (2005) found with a fully coupled atmosphere-ocean-land-sea ice model with full soil freeze-thaw processes that as little as 1.0 million $\mathrm{km}^{2}$ of near-surface permafrost would remain by 2100 under the A2 scenario instead of present-day 10.5 million $\mathrm{km}^{2}$. The Northern Hemisphere permafrost area was estimated to decrease by $12-22 \%$ for all permafrost types and by $12-34 \%$ for continuous permafrost by the year 2050 (Anisimov and Nelson, 1997); these numbers increase to one-third and a half, respectively, by the year 2100 (Demchenko et al., 2001; Poutou et al., 2004).

Such a large-scale reduction of permafrost areas in the future has huge implications for the evolution of the carbon balance of high latitude ecosystems. The depth and duration of seasonal thaw controls, for instance, the timing of the boreal forests growing season (Goulden et al., 1998; Zhuang et al., 2003). Frozen soils in tundra regions are generally rich in carbon, and so, if thawed, could release $\mathrm{CO}_{2}$ or $\mathrm{CH}_{4}$ back to the atmosphere. Boreal ecosystems contain about $25 \%$ of the total world soil carbon pool, or $375 \mathrm{GtC}$, in the permafrost and the seasonally thawed soil layer, as peat (Botch and Kobak, 1995) or in late quarternary loess deposits (Muhs and Bettis, 2003). These estimates take into account only the carbon in the upper soil meter, but carbon is sometimes present in even larger quantities below that depth (Zimov et al., 1997). Tarnocai (1999) estimated that upper soil Cryosols in Canada presently store $103 \mathrm{GtC}$ and would reduce in area by about $50 \%$ under a $4{ }^{\circ} \mathrm{C}$ increase in surface temperature, with the potential to release $50 \mathrm{GtC}$ to the atmosphere. According to Zimov et al. (1997), Zimov (2005) and Zimov et al. (2006), an amount of 400-500 GtC is stored in the loess deposits of the Yedoma in northeast Siberia. This is an area of $10^{6} \mathrm{~km}^{2}$ of carbonrich loess sediments accumulated during the Pleistocene, only partly thawed under thermokarst lakes in Holocene and released to the atmosphere in methane form.

Apart from climate warming-induced emissions through decomposition of organic matter $(\mathrm{OM})$, methane clathrates is another potential methane source. About $400 \mathrm{Gt}$ of methane are stored in sediments under permafrost regions. The release of methane and its subsequent oxidation to carbon dioxide may be responsible for the observed swings in atmospheric $\mathrm{CH}_{4}$ and $\mathrm{CO}_{2}$ concentrations during glacial times (e.g. MacDonald, 1990).

The rate at which frozen soil carbon can be released back to the atmosphere is a key-vault variable and has huge uncertainties. If the losses of frozen carbon are rapid enough to occur during the coming decades when most of fossil fuel reserves will continue to be used, one may expect a strong positive feedback on climate change. Assuming for instance the release of $400 \mathrm{Gt}$ during the coming century, half of which will get absorbed into the ocean, would add $50 \mathrm{ppm}$ of $\mathrm{CO}_{2}$ in the atmosphere. This is similar to the $\mathrm{CO}_{2}$ concentration difference between a fossil fuel intensive emission scenario and a more environmentally cautious one (IPCC, 2001). On the other hand, if the emissions from frozen soils are gradual in the future, the excess of $\mathrm{CO}_{2}$ will be absorbed more steadily by the ocean, preventing any dangerous levels of climate change to be reached.

We constructed an idealized 1-D soil model to simulate the fate of frozen carbon in permafrost. The model accounts for heat and gas transport in the soil column taking as boundary conditions the atmospheric climate at the top and the geothermal flux at the bottom. The dynamic evolution of the soil temperature, soil water content, and the active layer depth are calculated with a time step of $5 \mathrm{~d}$. The model accounts for soil carbon transformation to $\mathrm{CO}_{2}$ and methane driven by temperature if the soil is thawed. This idealized version of the model does not consider any active vegetation in the upper soil horizon (except for a moss layer playing the role of a thermal insulator). Therefore, the system studied is essentially a pile of frozen 'dead carbon' subject to changes in atmospheric temperature and precipitation. This corresponds to Yedoma conditions in the Northeast Siberia (Zimov et al., 1997; Zimov, 2005; Walter et al., 2006; Zimov et al., 2006).

The main originality of the model is that it takes into account the heat released during decomposition of $\mathrm{OM}$ by soil microorganisms. This process is important in the assessement of the vulnerability of frozen carbon in Arctic regions. Additional heat can act as a trigger to accelerate permafrost thawing This effect would considerably amplify the losses of $\mathrm{CO}_{2}$ and $\mathrm{CH}_{4}$ to the atmosphere as compared to the case where the heat supply is from the atmosphere only. The main question that we address in this paper is whether the heat released by microorganisms during oxic respiration or methanogenesis has the critical potential to cause an additional thawing of the soil below, and accelerate the transformation of permafrost carbon. The companion paper (Khvorostyanov et al., 2008) presents some applications of the model described here, in particular its sensitivity to the key parameters.

Section 2 describes the processes of heat conduction, freezing/thawing, and hydrology, Section 3 presents soil respiration, methanogenesis, methanotrophy, and methane ebullition, Section 4 describes diffusion and vertical advection of soil gases. 
Section 5 describes the model experiments performed to study the vulnerability of frozen carbon to a stepwise atmospheric warming signal, with and without heat produced by soil microorganisms. Section 6 presents the results of these experiments. We examine also the role of oxygen limitation on the rate of decomposition of OM. Section 7 discusses feedbacks and processes involved in the soil response to warming, outlines their sensitivity to climate conditions and model parameters. Section 8 concludes about the results.

\section{Soil physical processes}

The model describes the following processes: (1) Heat conduction taking into account soil moisture freezing and thawing (Poutou et al., 2004); (2) hydrology of the upper meter of the soil; (3) soil carbon transformation, the latter accomplished by means of oxic decomposition of soil OM and methanogenesis, both accompanied by heat generation; (4) methanotrophy; (5) vertical diffusion of oxygen and methane; (6) vertical transfer of gases due to pressure differences and (7) methane ebullition.

\subsection{Heat conduction}

The soil temperature is calculated with a thermal conductivity equation with heat sources:

$c \frac{\partial T(z, t)}{\partial t}=\frac{\partial}{\partial z}\left[k \frac{\partial T(z, t)}{\partial z}\right]+\sum_{i} \Lambda_{i} \kappa_{i} f_{i}(T) C(z, t)$

with boundary conditions:

$T(z=0, t)=f(\mathrm{SHB})$

$\frac{\partial T(z, t)}{\partial z}\left(z=z_{\max }\right)=\frac{f_{G}}{k}$,

where $T(z, t)$ is the soil temperature; $c(z, t)$ is the soil heat capacity; $k(z, t)$ is the soil heat conductivity; $\Lambda_{i}$ is the specific heat of OM oxidation, methanogenesis and methanotrophy for $i=1,2,3$, respectively; $\kappa_{i} f_{i}(T)$ describes the rate and the temperature dependency of these processes (see Section 3.2); $c(z$, $t$ ) — soil carbon density; $f_{G}$ is the geothermal heat flux equal to 57 $\mathrm{mW} \mathrm{m} \mathrm{m}^{-2}$, and SHB is the surface heat balance computed by the boundary layer scheme of the French Laboratory of Dynamical Meteorology atmospheric general circulation model (LMDz3.3 AGCM). Equation (1) takes into account diffusion of heat, freezing and thawing of soil water, and heat release accompanying oxic decomposition of dead organic matter (DOM), methanogenesis and methanotrophy.

Soil temperatures are calculated with a multilevel heat conduction scheme. Generally, 100 layers are used, the vertical discretization being calculated as a geometric series with layer thickness increasing toward the deeper layers. The depth of the soil levels has been chosen to fit the results of test simulations with 1000 equally spaced levels. The total soil depth in the Pleistocene soil configuration is $z_{\max }=12 \mathrm{~m}$. The equilibrium time scale of the deepest soil layer (that is, the e-folding time of the deepest layer to adjust to an instantaneous surface climate change) is about a few decades.

Soil heat capacity and conductivity are variable, depending on soil water and ice content. Their parametrizations have been described in detail by Poutou et al. (2004). The upper $20 \mathrm{~cm}$ of the soil are assumed to be a moss layer with a very high porosity of 0.92. Its summer heat conductivity is up to three to four times smaller than that in the underlying soil, so this layer serves as a soil thermo-isolator during the warm season.

The snow cover is taken into account when calculating the surface heat balance and soil hydrology. A snow layer develops above the soil during the cold season. Its mass balance depends on precipitation, evaporation, and melting. The latter depends on the surface energy balance. Heat conduction is calculated using the same number of levels as in the soil model. The heat conductivity of the snow layer is about three to four times smaller than that in the soil, so that snow serves as a thermal isolator during the cold season.

\subsection{Soil hydrology}

Soil humidity is treated by a bucket scheme with a depth of $1 \mathrm{~m}$ and a field capacity $f=0.5 \mathrm{~m}^{3}$ water $\mathrm{m}^{-3}$ soil. The usual value of $f$ is 0.15 , but here we use $f=0.5$ for compatibility with the soil porosity value of 0.5 measured for Pleistocene loess sediments around Cherskii (Romanovsky, 1993). The soil within the bucket cannot contain more than $f \mathrm{~m}^{3}$ of water per $\mathrm{m}^{3}$ of soil. The volumetric soil water content $\theta$ is calculated as a ratio of the water volume in $1 \mathrm{~m}^{3}$ of soil to $f$. The same $\theta$ value is applied to all vertical levels within the bucket depth (Poutou et al., 2004). Below the depth of $5 \mathrm{~m}$, the soil humidity is prescribed. For the Yedoma, which is extremely rich in ice, we assume $\theta=$ $100 \%$ when the soil is frozen and $35 \%$ when permafrost thaws (Romanovsky, 1993). Linear interpolation is used to compute the soil humidity between 1 and $5 \mathrm{~m}$.

\section{Soil organic matter decomposition model}

\subsection{Initial dead organic matter (DOM) stocks in Yedoma}

We consider three soil DOM pools called active, slow and passive. Each pool has different lability expressed in the decomposition rates $\kappa_{1, a s p}$ (see eqs 1 and 4). The decomposition rate associated with the slow pool $\kappa_{1, s}$ is 37 times smaller than that of the active pool. The passive pool is 1600 times slower than the active one (Krinner et al., 2005), that is,

$\kappa_{1, s}=\kappa_{1, a} / 37, \quad \kappa_{1, p}=\kappa_{1, a} / 1600$.

During the decomposition of each DOM pool part of the decomposed $\mathrm{OM}$ is oxidised to $\mathrm{CO}_{2}$, and another part is delivered to the other two pools. The degradation of $\mathrm{OM}$ of the active pool and transformation of a part into the slow pool depend on the 
prescribed soil clay content fraction (Krinner et al., 2005) that depends on the soil type and equals 0.18 for the case considered. The total soil carbon density $C(z, t)$ is the sum of the three carbon pools. Initial carbon distribution is $90 \%$ in the active pool, $10 \%$ in the slow pool, and $0 \%$ in the passive pool. This corresponds to the distribution of carbon among the soil pools after the decay of C3 herbaceous vegetation (Krinner et al., 2005), which approximates the 'mammoth steppe' present in the region during the Pleistocene (Zazula et al., 2003). Yedoma soils have been formed in a quite specific way. Fine-grained loess sediments mixed with remains of leaves and plant stems were accumulating rapidly driven by winds and then being buried perennially in the frozen ground. Therefore this organic matter is old but still highly labile and thus described primarily by the model's active carbon pool.

The initial soil carbon density $C_{0}=\left.C\right|_{t=0}$ in the DOM is prescribed the same throughout the whole depth of organic soil. We neglect the active carbon cycling in the seasonally thawed upper soil column, associated with the formation of litter, root exudation and decomposition of recent soil organic matter. In tundra soils, the rooting depth is rather shallow (Jackson et al., 1996), and such active carbon cycling concerns only the 20 uppermost centimetres near the surface. The total carbon mass stored within the upper soil layer is small compared to organic soil depth of $12 \mathrm{~m}$ typical for Pleistocene soils in the Yedoma region. With a typical NPP of tundra plants of $75 \mathrm{~g} \mathrm{Cm}^{-2} \mathrm{yr}^{-1}$, (e.g. Williams et al., 2000; Stolbovoi and McCallum, 2002), in a version of our model which includes tundra plants and recent carbon (see Part II, this issue) we would allocate $38 \mathrm{kgC} \mathrm{m}^{-3}$, or $8 \mathrm{kgC} \mathrm{m}^{-2}$ into the upper $\approx 20 \mathrm{~cm}$ of the soil after $1000 \mathrm{yr}$ of simulation. The total depth-integrated soil carbon density in a Pleistocene soil column is about $400 \mathrm{kgC} \mathrm{m}^{-2}$. Hence, all this carbon mass in the layer of soil carbon input constitutes only $2 \%$ of the total carbon. We also neglect the penetration of newly fixed carbon into the soil due to pedogenesis, estimated rate of which would be about $2 \mathrm{~mm} \mathrm{yr}^{-1}$ for Pleistocene carbon content of $2 \%$ of soil density and a typical tundra NPP of $75 \mathrm{gC} \mathrm{m}^{-2} \mathrm{yr}^{-1}$.

\subsection{Organic matter decomposition into $\mathrm{CO}_{2}$}

Dead organic matter is decomposed by microorganisms according to:

$\frac{\mathrm{d} C(z, t)}{\mathrm{d} t}=-\min \left[\kappa_{1} f_{1}(T) C(z, t), \frac{\mathrm{d} C_{\max }}{\mathrm{d} t}\right]-\kappa_{2} f_{2}(T) C(z, t)$,

where $\kappa_{i} f_{i}(T)$ is the rate of decomposition depending on temperature with $\kappa_{i}\left[\mathrm{yr}^{-1}\right]$ being the rate constant and $f_{i}(T)$ a nondimensional temperature dependency function. The $i$ index values correspond to oxic decomposition of soil organic matter or methanogenesis at $i=1,2$, respectively. Here $\mathrm{d} C_{\max }$ is the mass of carbon corresponding to that of available oxygen (see below).

The decomposition of DOM is limited by oxygen availability in each layer. The mass of soil carbon transformed at each time step $\mathrm{d} C$ cannot exceed the maximum mass $\mathrm{d} C_{\max }$ that could react with all the available number of moles of $\mathrm{O}_{2}$ :

$\mathrm{d} C_{\max }=\mathrm{O}_{2} v w_{C} / w_{\mathrm{O}_{2}}$,

where $\mathrm{O}_{2}$ is the mass of soil oxygen per $\mathrm{m}^{3}$ of air at a given depth, $v$ is the soil air content $\left(\mathrm{m}^{3} \mathrm{air} / \mathrm{m}^{3}\right.$ soil $)$, a function of soil humidity and porosity, $w_{\mathrm{C}}=12$ and $w_{\mathrm{O}_{2}}=32$ are molecular masses in grams of carbon and oxygen, respectively. Equation (5) implies a $1: 1 \mathrm{O}_{2}: \mathrm{CO}_{2}$ ratio in respiration processes, whereas it equals rather 1.1 according to Keeling et al. (1996) in photosynthetic assimilates.

Soil respiration increases with temperature. Microbes in the northern regions can remain active at the subzero temperatures if the unfrozen moisture is conserved in the soil (Clein and Schimel, 1995). However, this effect is currently neglected. According to measurements by Chuprynin et al. (2001) for the soil studied here, $f_{1}(T)$ can be approximated by a piecewise linear function that fits certain observed points of reference. The corresponding function $\kappa_{1} f_{1}(T)$ is shown in Fig. 1 by the thick solid curve.

Note that besides the linear increasing function of temperature chosen here, other parametrizations of the temperature dependency of soil organic matter decomposition are used in the literature. Among them are the so-called $Q_{10}$ exponential relationships, Arrhenius-type functions (e.g. Lloyd and Taylor, 1994), power functions (e.g. Ratkowsky et al., 1982) and the heat sum concept (e.g. Andrén and Paustian, 1987), the latter corresponding to $Q_{10}$ values exponentially decreasing with temperature. A review of those parametrizations, along with their fitting against measurements data and comparative analysis, is

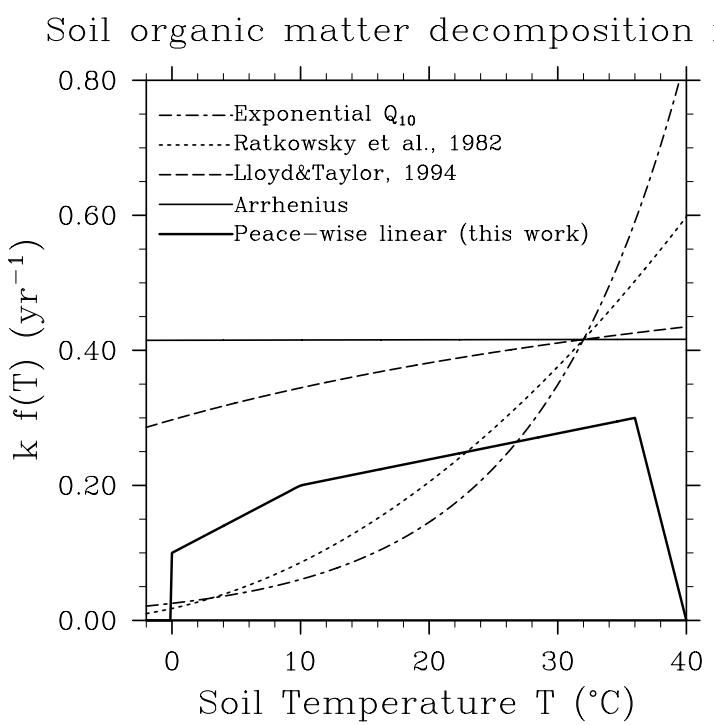

Fig. 1. Dependence of microbial oxic decomposition rate $\kappa_{1} f_{1}(T)$ on soil temperature. Other commonly used dependencies are shown for comparison: exponential $\mathrm{Q}_{10}$ function, Arrhenius-type function, a two-parameter function proposed by Lloyd and Taylor (1994), and the function proposed by Ratkowsky et al. (1982). 
presented in (Kaetterer et al., 1998). Figure 1 shows examples of these parametrizations with parameter values estimated by Kaetterer et al. (1998) for L-layer substrate in deciduous, forest, brown earth vegetation/soil. Note that the temperature dependency we use is the only one in Fig. 1 with no respiration below $0{ }^{\circ} \mathrm{C}$.

The specific heat $\Lambda_{1}$ released during oxic microbial decomposition is prescribed to $40 \mathrm{MJ} \mathrm{kgC}^{-1}$ according to Chuprynin et al. (2001),Hodgman (1960). The exact value of this parameter for Yedoma soils is unknown. The value we use in this study as a reference one is the largest of those given by Hodgman (1960) for organic matter, to illustrate the role of additional heating that accompanies decomposition of soil organic matter. However, if one takes the smallest of the values given by Hodgman (1960) (25 $\mathrm{MJ} \mathrm{kgC}^{-1}$ ), the system's behaviour remains essentially the same, with almost the same carbon amount mobilized, as shown by the sensitivity tests of the companion paper (fig. 7 of Part II).

Soil nutrients can play an important role in decomposition processes, providing additional feedbacks in the soil response to atmospheric warming. The sign of the total soil-vegetation system response to the warming is controversial (e.g. Waelbroeck et al., 1997; Mack et al., 2004). Since the current model version does not contain interactive vegetation, and we focus on the decomposition of already accumulated soil carbon stock, we do not consider explicitly nutrient limitations of decomposition. However the incubation experiments, which are the basis for the model parametrizations, already take into account nitrogen content, since it was present in the analysed samples.

\subsection{Methane processes: methanogenesis and methanotrophy}

At low oxygen content, we assume that methanogenesis develops. Only the most labile litter, that is, the active carbon pool can be decomposed by methanogenesis. Its temperature dependence is determined by the same function as that for soil respiration $\left(f_{2}(T)=f_{1}(T)\right)$. The rate of methane generation is parametrized as:

$\kappa_{2}=\frac{\kappa_{1}}{10} e^{-\mathrm{O}_{2, p} / \mathrm{O}_{2}^{*}}$,

where $\mathrm{O}_{2, p}$ is oxygen concentration per unit porous volume, $\mathrm{O}_{2}^{*}$ is an e-folding oxygen concentration assumed to be $2 \mathrm{~g} \mathrm{~m}^{-3}$. This value is taken from the results of Duval and Goodwin (2000) where methanogenesis was observed to decrease sharply at dissolved oxygen concentrations higher than $2 \mathrm{mg}^{-1}$. The factor of 10 corresponds to methanogenesis estimates under anoxic conditions, according to which the rate of methanogenesis is 10 times lower than that of oxic decomposition of soil organic matter (Zimov et al., 2004). Methanogenesis specific heat is taken to be $5.5 \mathrm{MJ} \mathrm{kgC}^{-1}$ corresponding to the reaction of methane formation from glucose:

$\mathrm{C}_{6} \mathrm{H}_{12} \mathrm{O}_{6} \rightarrow 3 \mathrm{CO}_{2}+3 \mathrm{CH}_{4}+396 \mathrm{~kJ}$, with heat release of $132 \mathrm{~kJ} \mathrm{~mol}^{-1} \mathrm{CH}_{4}$ following Schlegel(1992). Note that in reality there is no single reaction transforming organic matter into the end products $\mathrm{CO}_{2}$ and $\mathrm{CH}_{4}$, since no microbial species is able to accomplish this reaction on its own. Complex organic molecules are consecutively degraded by many different microbial species in a substrate food chain (Conrad, 1989). Equation (7) shows in particular that one mol $\mathrm{CO}_{2}$ is produced per mol $\mathrm{CH}_{4}$ during methanogenesis.

When there is enough oxygen to react with methane, generally in the most aerated upper-soil layers, we assume that methanotrophy develops. This process results in a net consumption of $\mathrm{CH}_{4}$ coming from both the atmosphere and the soil

$\mathrm{CH}_{4}+2 \mathrm{O}_{2} \rightarrow \mathrm{CO}_{2}+2 \mathrm{H}_{2} \mathrm{O}+802 \mathrm{~kJ}$.

We use a methanotrophy time constant of $5 \mathrm{~d}$. This yields a simulated $\mathrm{CH}_{4}$ uptake for mid-latitudes that falls between the values reported by Price et al. (2003) and Koschorrek and Conrad (1993), which vary by an order of magnitude. The time constant does not depend on temperature, but the temperature must be above $0{ }^{\circ} \mathrm{C}$ for methanotrophy to occur (Koschorrek and Conrad, 1993; Price et al., 2003). The specific heat released by methanotrophy is $50 \mathrm{MJ}\left(\mathrm{kgCH}_{4}\right)^{-1}$.

\section{Transport of soil gases}

\subsection{Diffusion of soil oxygen and methane}

Since the production of both $\mathrm{CO}_{2}$ and $\mathrm{CH}_{4}$ depend on oxygen availability in each soil horizon, the processes of oxygen diffusion and transformation are explicitly taken into account in the model. The prognostic equation for oxygen diffusion has the form:

$$
\begin{aligned}
\epsilon_{\mathrm{O}_{2}} \frac{\partial \mathrm{O}_{2}(z, t)}{\partial t}= & \frac{\partial}{\partial z}\left[D_{\mathrm{O}_{2}} \frac{\partial \mathrm{O}_{2}(z, t)}{\partial z}\right]-\left.\frac{1}{\epsilon_{\mathrm{O}_{2}}} \frac{w_{\mathrm{O}_{2}}}{w_{C}} \frac{\partial C}{\partial t}\right|_{\text {oxic }} \\
& -\left.2 \frac{\partial \mathrm{CH}_{4}}{\partial t}\right|_{\mathrm{MT}} \frac{w_{\mathrm{O}_{2}}}{w_{\mathrm{CH}_{4}}} \frac{\epsilon_{\mathrm{O}_{2}}}{\epsilon_{\mathrm{CH}_{4}}} .
\end{aligned}
$$

Here $\epsilon_{\mathrm{O}_{2}}$ and $\epsilon_{\mathrm{CH}_{4}}$ are the total oxygen and methane porosities (e.g. Tans, 1998), respectively, linking the gas concentration per air volume, which is the model prognostic variable, with that per soil volume. These quantities take into account both the gas in the air-filled pores and the gas dissolved in the water-filled pores. The total oxygen porosity is given by $v+\theta \pi_{s} B_{\mathrm{O}_{2}}$, where $\pi_{s}$ is soil porosity, $B_{\mathrm{O}_{2}}$ is the Bunsen coefficient of oxygen, the molar density of the dissolved gas in water divided by the molar density in air, at equilibrium at local temperature and pressure. It equals 0.038 at normal pressure and $10{ }^{\circ} \mathrm{C}$ (Hodgman, 1960). The gas concentration in the water-filled pores equals $B_{\mathrm{O}_{2}} \mathrm{O}_{2}$, while the concentration per soil volume is $\epsilon_{\mathrm{O}_{2}} \mathrm{O}_{2}$. The quantities $\left.\frac{\partial C}{\partial t}\right|_{\text {oxic }}$ and $\left.\frac{\partial \mathrm{CH}_{4}}{\partial t}\right|_{\mathrm{MT}}$ are, respectively, the rates of respiration and methanotrophy, which consume oxygen. The initial condition of 
eq. (8) is

$\left.\mathrm{O}_{2}\right|_{t=0}=266 \mathrm{~g} \mathrm{~m}^{-3}$

and the boundary condition is

$\left.\mathrm{O}_{2}\right|_{z=0}=\frac{p_{s}}{R T_{s}} \mathrm{O}_{2 s} w_{\mathrm{O}_{2}}$

defined by atmospheric surface pressure $p_{s}$, temperature $T_{s}$ and a mixing ratio $\mathrm{O}_{2 s}$ of $20.9 \%$. This boundary condition implies that the atmosphere is an infinite reservoir of oxygen.

The diffusivity $D_{\mathrm{O}_{2}}$ of oxygen in the soil profile is expressed in terms of its diffusivity in free air $D_{\mathrm{O}_{2, a}}$ and in water $D_{\mathrm{O}_{2, w}}$ as

$D_{\mathrm{O}_{2}}=\left(D_{\mathrm{O}_{2}, a} v+D_{\mathrm{O}_{2}, w} \theta \pi_{s} B_{\mathrm{O}_{2}}\right) \eta$,

where $\eta$ is a tortuosity factor assumed to be $2 / 3$ following Hillel (1980). The free-air oxygen diffusivity $D_{\mathrm{O}_{2, a}}=1.596 \times$ $10^{-5} \mathrm{~m}^{2} \mathrm{~s}^{-1}$ according to Marreto and Mason (1972), and the diffusivity in water is $1.6 \times 10^{-9} \mathrm{~m}^{2} \mathrm{~s}^{-1}$.

A similar equation as eq. (8) is used to describe the diffusion of methane in the soil with boundary and initial conditions corresponding to the atmospheric $\mathrm{CH}_{4}$ concentration of $9.4 \times$ $10^{-4} \mathrm{~g} \mathrm{~m}^{-3}$ and mixing ratio of $1.7 \mathrm{ppm}$. The free-air diffusivity of methane is $1.702 \times 10^{-5} \mathrm{~m}^{2} \mathrm{~s}^{-1}$ according to Marreto and Mason (1972), the diffusivity in water is $2 \times 10^{-9} \mathrm{~m}^{2} \mathrm{~s}^{-1}$, and the Bunsen coefficient $B_{\mathrm{CH}_{4}}=0.043$ (Wiesenburg and Guinasso, 1979).

\subsection{Gas flux due to pressure difference}

Methanogenesis, methanotrophy and oxic microbial decomposition (see Section 3.2) can modify the total gas pressure in the soil. When new molecules of a gas are added to the soil in the course of a reaction, the partial pressure of the gas is modified changing the total pressure and thus creating a pressure gradient in the soil. Consider the following simplified processes:

$B \rightarrow 3 \mathrm{CO}_{2}+3 \mathrm{CH}_{4}$

$\mathrm{CH}_{4}+2 \mathrm{O}_{2} \rightarrow \mathrm{CO}_{2}+2 \mathrm{H}_{2} \mathrm{O}$

$B+\mathrm{O}_{2} \rightarrow B^{\prime}+\mathrm{CO}_{2}$

Here, $B$ and $B^{\prime}$ represent (partially decomposed) organic soil matter molecules. Anoxic microbial decomposition and associated methanogenesis (reaction 12) will produce six molecules of gas per reaction; methanotrophy (reaction 13) will consume two molecules of gas per reaction; oxic decomposition (14) will not modify the total gas pressure. During these processes, gas pressure within the soil can therefore change with respect to ambient surface pressure. Given the very low dynamic viscosity of air, one can suppose that any gas pressure difference between the subsurface pore space and surface air will equilibrate very rapidly, in less than a day or so, by in- and outflow of gas through the soil surface. In our model, this process is taken into account as an immediate gas exchange in case a pressure disequilibrium occurs. In case of net total gas production (consumption) in soil layer $n$, the gas column in layers 1 to $n-1$ is shifted upwards (downwards) to free pore space for the excess gas (occupy the empty pore space). This procedure is applied successively from the bottom layer to the top of the soil. Any excess of soil gas remaining after the top level has equilibrated is lost to the atmosphere. Conversely, any deficit of gas in the top soil layers is replaced by air with ambient atmospheric $\mathrm{CH}_{4}$ and $\mathrm{O}_{2}$ concentrations, yielding the corresponding flux of $\mathrm{CH}_{4}$ into the soil. This procedure avoids adding a pressure gradient term to the implicit numerical scheme for the gas diffusion equations.

No matter is exchanged at the lowermost boundary of the soil model. Not taking into account this process can lead to erroneously high $\mathrm{CH}_{4}$ partial pressure - in excess of the barometric surface air pressure-in the lower soil levels during periods of strong methanogenesis. The methane flux during these periods sometimes reaches up to a few $\mathrm{gCH}_{4} \mathrm{~m}^{-2} \mathrm{~d}^{-1}$. The contribution of the methane flux due to pressure differences to the total $\mathrm{CH}_{4}$ flux is small.

This immediate pressure equilibration also allows to take into account ventilation of the soil through surface air pressure variation in time (Sowers et al., 1992). The methane flux variations caused by synoptic pressure changes $\left(10 \mathrm{mb} \mathrm{d}^{-1}\right)$ are of the order of $5 \mathrm{mgCH}_{4} \mathrm{~m}^{-2} \mathrm{~d}^{-1}$ at $\pi_{s}=0.5$ and soil depth of $10 \mathrm{~m}$.

\subsection{Methane ebullition}

When methane concentration $\mathrm{CH}_{4}$ exceeds a certain threshold value $\mathrm{CH}_{4, \max }$, bubbles are formed in water-filled pores. The value $\mathrm{CH}_{4, \text { max }}$ is assumed to change between 500 and $1000 \mu \mathrm{M}$ ( 8 to $16 \mathrm{mg} \mathrm{m}^{-3}$ ) corresponding to totally vegetated and unvegetated soil, respectively (Walter and Heimann, 2000). We choose the value of $12 \mathrm{mg} \mathrm{m}^{-3}$ for tundra soil.

The soil water is assumed to be dispersed in the pores forming 'droplets' that occupy a number of adjacent soil pores. So one can consider groups of water-filled pores alternating with groups of air-filled pores. Once a bubble formed within a group of waterfilled pores meets a group of air-filled pores on its way through a model layer it escapes from the water and the methane it carries is left within the layer. The probability that the bubble escapes from the layer and thus removes methane from it is $P_{N}=\theta^{N}=$ $\theta^{\delta z /(\eta \eta)}$, where $\theta$ is the layer humidity, $N$ is the number of groups of water- and air-filled pores, $\delta z$ is the layer thickness, $l$ is the size of water 'droplets' dispersed in the soil, that is, of groups of water-filled pores. The latter is assumed to be the same for the groups of air-filled pores. Its value is taken equal to $1 \mathrm{~cm}$. The tortuosity $\eta$ takes into account the fact that the way of a bubble in the soil is not a straight line owing to the pores.

So $P_{N}$ times the number of bubbles formed will pass through the layer transferring $P_{N}\left(\mathrm{CH}_{4}-\mathrm{CH}_{4, \max }\right)$ of methane to the upper layer. Methane thus removed from the uppermost model layer forms the ebullition flux. 



Fig. 2. Step forcing experiments. (a) Surface forcing: precipitation (left-hand axis, grey curve) and temperature (right-hand axis, black curve), 10-yr running means. (b) Depth-integrated soil carbon density: thick and thin lines correspond to decomposition heating 'On' and 'Off', respectively; (dotted) no oxygen limitation; (dashed) oxygen limitation, no methane; (solid) oxygen limitation with methane. The three thin lines coincide. Vertical lines show the time periods zoomed in Fig. $4 \mathrm{a}-\mathrm{c}$.

\section{Model experiments to test the impact of heat generation}

The model is forced using the data of the Climate Research Unit of the University of East Anglia (http://www.cru.uea.ac.uk/) on the surface wind speed, total cloud cover, surface air temperature (at $2 \mathrm{~m}$ ) and its amplitude, surface air relative humidity, monthly precipitation, and number of precipitation days. To obtain the data corresponding to a climate with double atmospheric $\mathrm{CO}_{2}$ concentration (see below), anomalies of these quantities computed as differences between present-day and $2 \times \mathrm{CO}_{2}$ simulations with LMDz3.3 model have been added to the observed fields (Poutou et al., 2004). On the basis of this data the 'weather generator' of Jon Foley (personal communication) based on the model of Richardson and Wright (1984) generates 5-d variability of temperature, precipitation, wind velocities, etc. These variables are then used to calculate the surface heat balance in eq. (2) to force the soil model.

To study an example of the process of decomposition of soil organic matter in response to future warming we chose a point located at $101.5^{\circ} \mathrm{E}, 59.3^{\circ} \mathrm{N}$ in southern central Siberia. (At the same time the region of interest in terms of realistic assessment of the $\mathrm{CO}_{2}$ and methane fluxes and their contribution to the global carbon balance is the northeastern Siberia containing great amounts of loess sediments rich in organic carbon accumulated during the Pleistocene, the so-called Yedoma Ice Complex.) Average organic soil depth is $12 \mathrm{~m}$, and maximum measured depth attains $80 \mathrm{~m}$ in the Yedoma region. Organic carbon density is about $33 \mathrm{kgC} \mathrm{m}^{-3}$, or $2 \%$ of the soil density (Zimov et al., 2006). For this part of the study we are interested to investigate the conditions of a positive feedback between warming and the soil response, which are very sensitive to local climate. For the point selected, the surface temperatures are close to $0{ }^{\circ} \mathrm{C}$ under the future equilibrium state corresponding to $2 \times \mathrm{CO}_{2}$ concentration. As will be shown, at such surface temperatures, the role of an additional heat release that accompanies organic matter decomposition is essential for the decomposition to be intense and self-sustaining. Although organic carbon depth is probably substantially smaller at this location, we use the same organic carbon depth as for the Pleistocene soil $(12 \mathrm{~m})$ to study the processes capable of creating the feedbacks.

To test the possibility of microbial 'self-heating' amplifying the external warming signal by an additional heating that causes fast decomposition of soil organic matter and methanotrophy, we studied the soil carbon response to a stepwise warming followed by return to the original climate conditions. Present-day climate conditions have been used to initialize the model for the first $1000 \mathrm{yr}$, then the ' $2 \times \mathrm{CO}_{2}$ ' climate forcing was applied for $50 \mathrm{yr}$ followed by normal conditions again during $1000 \mathrm{yr}$ (Fig. 2a). The reference case includes heat generation from DOM decomposition, methane processes and oxygen limitation. Two additional model sensitivity tests are performed. (1) No oxygen limitation, that is, the soil organic matter is decomposed irrespectively of oxygen availability. The methane processes are neglected in this case. (2) The oxygen limitation is included, but no methane processes occur. For each of the above-mentioned cases we compare scenarios with and without the 'self-heating' process that accompanies organic matter decomposition and methanotrophy.

\section{Results}

\subsection{Reference case}

Consider first in some detail the reference case, when both methane processes and decomposition heating are taken into account. Until about $30 \mathrm{yr}$ after the warming, most of the deep soil remains frozen and thaws gradually due to diffusion of heat from the surface (Fig. 3a). The soil organic matter is decomposed in the top soil (Fig. 3c) due to active layer deepening in response 


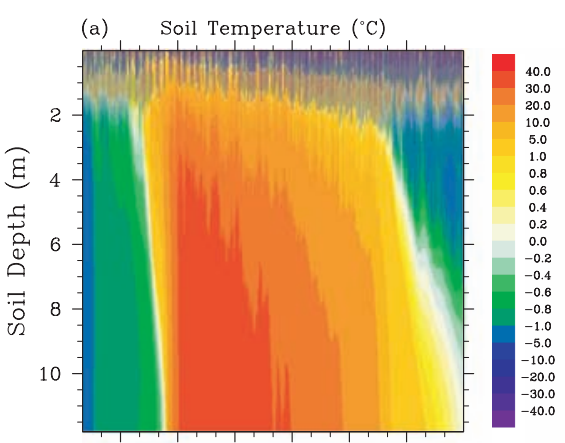

102010501080111011401170

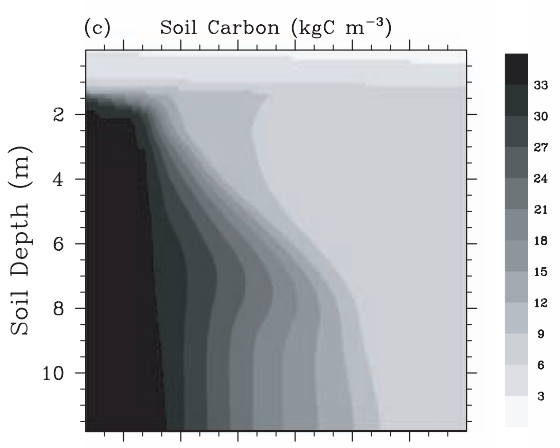

102010501080111011401170

(e) Soil Respiration $\left(\mathrm{gC} \mathrm{m}^{-3} \mathrm{day}^{-1}\right)$

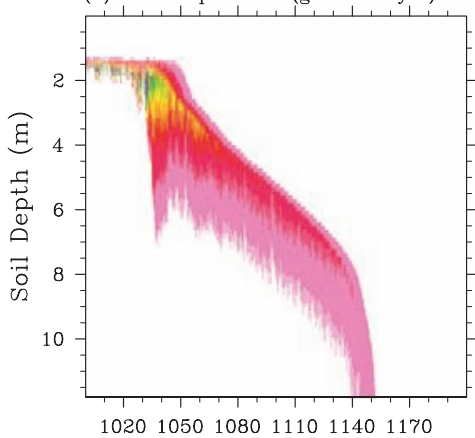

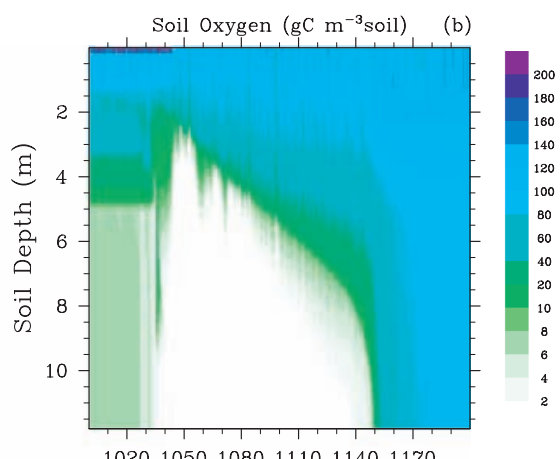

102010501080111011401170
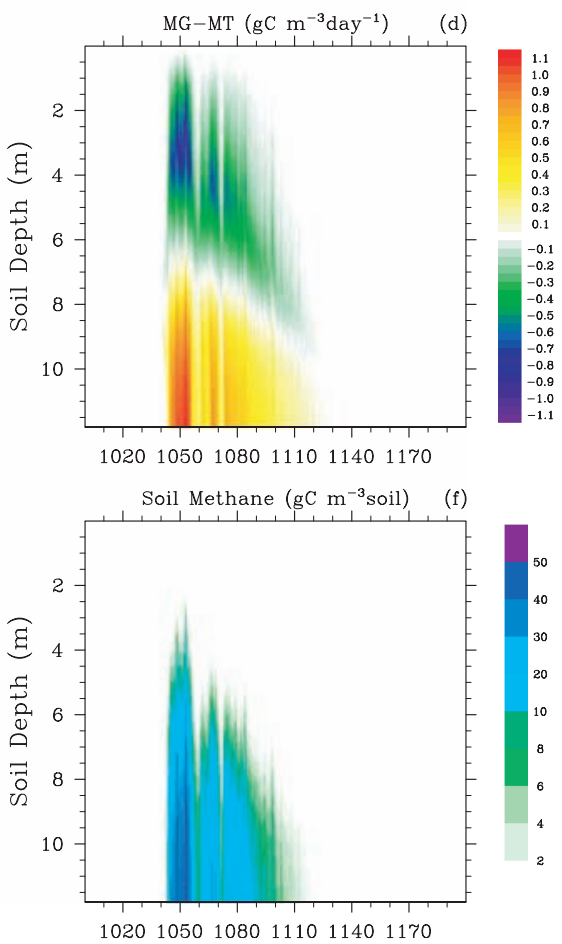

Fig. 3. Time evolution of vertical profiles of the main soil parameters when decomposition heat and methane processes are present: (a) soil temperature; (b) oxygen; (c) carbon density; (d) methanogenesis (positive values) and methanotrophy (negative values) rates; (e) soil respiration rate and (f) soil methane.

to $2 \times \mathrm{CO}_{2}$ climate. When the soil is frozen, heat conductivity is high, up to $4 \mathrm{~W} \mathrm{~m}^{-1} \mathrm{~K}^{-1}$, since half of the soil volume is filled by ice. There is a permanent heat inflow from the oxic decomposition layers into a progressively deepening active layer. Heat diffuses into the soil, and temperature rises gradually, almost homogeneously, below the active layer in the upper few soil meters. As soon as permafrost thaws, soil respiration immediately starts heating the soil and accelerates permafrost thawing. By the year 1030 soil temperatures are close to zero in the upper few soil meters. The heat released by respiration in summer is sufficient to prevent winter freezing. Starting from winter 1033 a layer that does not freeze in winter, a so-called talik forms in the soil (Fig. 4a) and deepens during following years. Consequently, intense respiration of more than $5 \mathrm{gC} \mathrm{m}^{-3} \mathrm{~d}^{-1}$ occurs between 2 and $4.5 \mathrm{~m}$ (Fig. 3e). The decomposition then continues and accelerates in depth (Fig. 3c and e). Below $4 \mathrm{~m}$, respiration becomes limited by available oxygen (Fig. 3b), triggering intense methanogenesis below $6.5 \mathrm{~m}$ attaining its maximum by year 1050 with values of more than $1.1 \mathrm{gC} \mathrm{m}^{-3} \mathrm{~d}^{-1}$ below $11 \mathrm{~m}$ and adding supplementary heat (Fig. 3d). Methane concentration reaches up to $50 \mathrm{gCH}_{4} \mathrm{~m}^{-3}$ there (Fig. 3f). Part of the methane escapes from the soil being transformed to $\mathrm{CO}_{2}$ by methanotrophy (Fig. 3d). Soil being warmed up by decomposition supplementary heat, resulting soil temperature attains up to $40^{\circ} \mathrm{C}$ (Fig. 3a). Decomposition and related fluxes remain intense until most of soil carbon is transformed. By the year 1160, carbon density is between 3 and $6 \mathrm{kgC} \mathrm{m}^{-3}$, or about $15 \%$ of initial carbon density. As our sensitivity tests have shown (see Part II), both methanogenesis and respiration are rather sensitive to the carbon content. So when it becomes low, respiration does not exceed $0.5 \mathrm{gC} \mathrm{m}^{-3} \mathrm{~d}^{-1}$, and 



Fig. 4. Soil temperature plots showing talik formation (a, c) and permafrost restoring (b, d) with (a, b) and without (c, d) decomposition heat. Contour interval is $4{ }^{\circ} \mathrm{C}$. Soil carbon density (e) and soil respiration rate (f) without decomposition heat. Note that the time and depth scales are different between $(a-d)$ and $(e-f)$.

methanogenesis has returned to zero. Soil heating is weakened through attenuation of soil organic matter decomposition processes, and the soil freezes again (Fig. 4b) due to diffusion of cold from the surface. The freezing is later accelerated by increased heat conductivity of the frozen ice-rich soil. When there is no decomposition heating, active layer deepens with respect to the present-day climate forcing, but heat diffusion from the surface alone is not enough to thaw the permafrost, trigger deep-soil respiration and carbon mobilization (Fig. $4 \mathrm{c}-\mathrm{f}$ ).

Figure $2 \mathrm{~b}$ shows the depth-integrated soil carbon as a function of time for the selected period after the warming for the six sensitivity cases described in Section 5. In all three cases, there is a major difference between the scenarios with and without 'self-heating'. When the latter is taken into account, organic matter decomposition continues after warming terminates and reaches equilibrium some time later in the first phase. Before the intense decomposition starts, some time is required until the soil is warmed up and ready for deep respiration. With no microbial heating decomposition stops shortly after the warming. Decomposition patterns are identical for the three cases (Fig. 2b). This illustrates that decomposition 'selfheating' is an essential process to account for, capable of fostering a self-sustainable mobilization of soil carbon under certain circumstances. 



Fig. 5. Soil temperature, carbon and respiration without oxygen limitation (a, c and e) and with oxygen limitation but no methane (b, d and f) with microbial heating present. Soil respiration rate in Fig. 5e attains up to $12 \mathrm{gC} \mathrm{m}^{-3} \mathrm{~d}^{-1}$.

\subsection{No oxygen limitation}

This case is displayed by dashed lines in Fig. $2 \mathrm{~b}$. When microbial heating is 'On', about $70 \%$ of soil carbon existing $\approx 30 \mathrm{yr}$ after warming is 'burnt' in $75 \mathrm{yr}$ (Fig. 2b), as soon as the soil is heated enough to allow very intense deep-soil respiration with rates of up to $12 \mathrm{kgC} \mathrm{m}^{-3} \mathrm{~d}^{-1}$ just after year 1030 (Fig. 5e). About $227 \mathrm{kgC} \mathrm{m}^{-2}$ are thus decomposed which gives an average carbon flux of $3 \mathrm{kgC} \mathrm{m}^{-2} \mathrm{yr}^{-1}$ during these $75 \mathrm{yr}$. Below the active layer carbon density drops by about $22 \mathrm{kgC} \mathrm{m}^{-3}$ on average by year 1105 (Fig. 5c).

The highest temperatures of more than $40{ }^{\circ} \mathrm{C}$ are reached in the case with no oxygen limitation when decomposition heat is present (cf. Figs. 3a, 5a and b). The great warming signal in the deep soil results from very strong respiratory heat release.
The highest temperatures are observed in the lower part of the soil where the heat is accumulated, rather than at the location of the strongest soil respiration about $2.5 \mathrm{~m}$ depth (Fig. 5a). This can be explained by the proximity of the layer of winter freezing. Decomposition of soil organic matter continues till about year 1140, when the soil carbon reaches an equilibrium value of $90 \mathrm{kgC} \mathrm{m}^{-2}$.

In the absence of microbial heating decomposition stops as soon as the present-day climate forcing is restored. Soil organic matter is decomposed due to active layer deepening only, similar to the case shown in Fig. 4c, f. The soil remains perennially frozen below $2 \mathrm{~m}$ depth. During $100 \mathrm{yr}$ after the warming onset, only $3 \%$ of depth-integrated soil carbon has been transformed to $\mathrm{CO}_{2}$ and $\mathrm{CH}_{4}$ versus $70 \%$ in the scenario with microbial heating 'On'. 


\subsection{Impact of oxygen limitation}

Oxygen limitation inhibits organic matter decomposition (cf. Fig. 5 left- and right-hand panels). Maximum soil temperature attains $26{ }^{\circ} \mathrm{C}$ versus more than $40{ }^{\circ} \mathrm{C}$ without oxygen limitation. Maximum soil respiration rate approaches $5 \mathrm{kgC} \mathrm{m}^{-3} \mathrm{~d}^{-1}$ versus more than $12 \mathrm{kgC} \mathrm{m}^{-3} \mathrm{~d}^{-1}$. Approximate soil carbon equilibrium is attained about $100 \mathrm{yr}$ later than without oxygen limitation. The mean carbon flux between year 1030, when deepsoil respiration starts, and 1240, when approximate equilibrium is reached, is about $1.3 \mathrm{kgC} \mathrm{m}^{-2} \mathrm{yr}^{-1}$ or more than two times less than without $\mathrm{O}_{2}$ limitation. The total amount of soil carbon transformed into gases since the rapid warming onset is however slightly greater: 272 versus $261 \mathrm{kgC} \mathrm{m}^{-2}$. Probably this is because less heat is lost by the soil due to high vertical temperature gradients during the more moderate soil warming in the presence of oxygen limitation. Soil respiration is now very intense only within a narrow range of depths: between 2 and $3 \mathrm{~m}$, where there is not only much carbon, but also enough oxygen. Respiration decreases with depth, alongside with $\mathrm{O}_{2}$ availability (Fig. 5f). Permafrost conditions are restored back quickly after the elevated respiration period is over.

\subsection{Impact of methane processes}

When methane processes are taken into account, the total amount of soil carbon decreases by the same value as in the case without methane processes, but the decomposition is faster, since intense methanogenesis accelerates soil carbon loss. Approximate equilibrium is reached by the year 1200 , about $40 \mathrm{yr}$ earlier than in the case with no methane processes. The mean carbon flux during 1030 and 1200 is $1.5 \mathrm{kgC} \mathrm{m}^{-2} \mathrm{yr}^{-1}$, or 1.2 times larger than without methane processes but yet two times smaller than without $\mathrm{O}_{2}$ limitation.

Deep soil respiration patterns are quite similar with and without methane processes (compare Figs. 3e and 5f). Soil temperatures are a few degrees warmer from 1030 to 1200 below the active layer (about $2 \mathrm{~m}$ ), when methane processes are included. Where $\mathrm{O}_{2}$ concentration is sufficiently low below $6.5 \mathrm{~m}$, respiration weakens, and methanogenesis starts. This process decreases soil carbon amount and allows to release more heat into the soil (Fig. 3d). As a result, the soil is warmed up faster and deeper than in the absence of methane processes. Like in the other two cases with 'self-heating', the decomposition of organic matter continues even after the surface conditions are restored, until there is too little carbon to feed the process. Methanogenesis, once started, maintains itself due to the heat it releases and is not limited by oxygen. The positive feedback on frozen carbon mobilization can thus be activated. Carbon availability and diffusion of cold from the surface are the limiting factors to this feedback.

\section{Discussion and role of decomposition heat generation}

In the absence of heat generation, the curves showing the depthintegrated carbon content in Fig. $2 b$ coincide for all the three cases. The temperature evolutions are also identical (not shown). The active layer deepens from 1 to $2 \mathrm{~m}$ only, and the mean deep soil temperature rises from about -6 to $-1{ }^{\circ} \mathrm{C}$ during the warming. Then colder temperatures restore within a few decades after the warming terminates. If the same forcing is prolongated beyond the $50 \mathrm{yr}$, the mean soil temperature below $2 \mathrm{~m}$ comes to an equilibrium of $-0.5^{\circ} \mathrm{C}$ by the year 1300 , and permafrost would not thaw for at least next $1000 \mathrm{yr}$. The heat diffusion from the surface alone during the $2 \times \mathrm{CO}_{2}$ warming is therefore not strong enough to thaw the permafrost and to start intense deepsoil respiration and methanogenesis. Therefore, the soil carbon and temperature evolution are almost identical in the three cases without decomposition heating.

In summary, taking into account microbial heating is essential to trigger a positive feedback between soil warming and decomposition of organic matter. Availability of oxygen and processes involving methane are also important in controlling the system's behaviour, time evolution and carbon losses.

However, the system's behaviour is also determined to a large extent by local climate and soil conditions, the geographical point in our case. The feedback would not start in sufficiently cold conditions, while all the soil organic matter would be decomposed rapidly even in the absence of microbial heating in sufficiently warmer conditions. Depending on the latitude, it is possible to decompose either most of the soil organic matter at present-day climate conditions (southwestern regions of Siberia) or, in contrary, less than half of the initial carbon content even after the $2 \times \mathrm{CO}_{2}$ climate warming (northeastern regions). The absence of methanogenesis and intense deep-soil respiration is typical of colder climates, where the decrease in soil carbon density will take place only via active layer deepening in response to a warmer climate. The choice of a geographical point (Section 5) to the southwest of Yedoma location is equivalent in this context to forcing the model with a warmer climate than that corresponding to $2 \times \mathrm{CO}_{2}$ scenario. For instance, an additional surface temperature anomaly of about $4.5{ }^{\circ} \mathrm{C}$ would be required to trigger the irreversible carbon mobilization in the area of Yakutsk $\left(130^{\circ} \mathrm{E}\right.$, $62^{\circ} \mathrm{N}$ ) at the western branch of Yedoma. (Annual mean surface air temperature changes by about $5{ }^{\circ} \mathrm{C}$ between present-day climate and $2 \times \mathrm{CO}_{2}$ forcing.)

The sensitivity tests performed for our model (see Part II for more details) indicate that simulated mobilization of soil carbon is also highly sensitive to initial carbon density, soil heat conductivity, soil respiration specific heat, soil porosity and moss layer porosity. The dependencies of soil carbon transformation on the parameters that control soil heating, freezing and respiration are characterized by rapid increase or decrease in the vicinity of a 


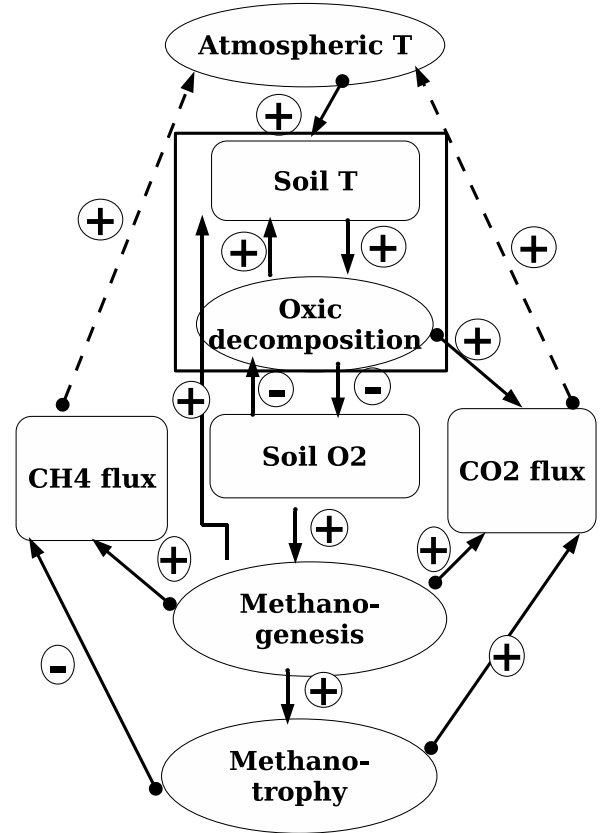

Fig. 6. Scheme of the interactions between atmospheric warming and permafrost processes.

certain threshold value. This corresponds to large variations in accumulated value of methane flux that is almost zero on the lower side of the threshold.

Figure 6 describes schematically the mechanism of the permafrost carbon transformation feedback. Atmospheric warming leads to an initial soil temperature rise due to heat diffusion. When permafrost thaws, respiration starts producing additional heat and thus further increases soil temperature. The higher the soil temperature the stronger the decomposition and more $\mathrm{CO}_{2}$ emitted to the atmosphere. Respiration consumes soil oxygen at the same time and slows down in the lack of oxygen. When soil oxygen becomes limiting (see eq. 4), methanogenesis starts, producing methane flux, contributing to $\mathrm{CO}_{2}$ flux, and additional, although smaller, soil heating. A large part of methane gets transformed though into $\mathrm{CO}_{2}$ by methanotrophy in the upper soil layers.

\section{Concluding remarks}

We developed a physical model to study the processes related to the permafrost carbon cycle, its sensitivity to climate warming, and soil carbon losses to the atmosphere in the form of $\mathrm{CO}_{2}$ or methane.

One can identify three main stages in the decomposition of soil organic matter, according to the rate and the processes involved. Organic matter is first decomposed more gradually due to active layer deepening caused by heat diffusion from the surface and additional soil heating that accompanies respi- ration. Then, when the soil temperatures are close to zero in the upper soil meters, and the respiration heat released in summer is high enough to prevent winter freezing, intense respiration starts. Decomposition continues from the depth as well and accelerates. When oxygen is consumed by respiration, and the latter cannot proceed strongly enough, intense methanogenesis can occur, where permafrost is thawed, contributing to rapid decomposition. Finally, when soil carbon density in the deep soil becomes low, the decomposition slows down again.

A self-sustaining positive feedback between the warming and respiration of soil organic matter can occur under certain conditions. The heat release accompanying microbial decomposition can help thaw permafrost and thus liberate more soil for further decomposition. This heat release can be sufficient to sustain the process when the external forcing is terminated.

The existence of this feedback and its parameters are sensitive to local climate conditions, availability of oxygen, methanogenesis and methanotrophy. It does not occur in sufficiently cold surface temperatures, while most of the soil organic matter is decomposed rapidly even in the absence of microbial heating in sufficiently warmer climate. The oxygen limitation inhibits decomposition of soil organic matter being a restricting force for the feedback in the absence of methane. Methanogenesis accelerates self-sustaining permafrost thawing and decomposition of soil organic matter, when external forcing is terminated.

The long-term simulations of this work have been performed for a location in Siberia $\left(101.5^{\circ} \mathrm{E}, 59.3^{\circ} \mathrm{N}\right)$ with a sufficiently warm climate in comparison with most of the Northeast Siberia rich in Pleistocene loess sediments. At the same time the organic carbon depth of $12 \mathrm{~m}$ typical for the mentioned region and used in this study appears to be too large value for the given location. These parameters have been used to show the processes that can be important for soil carbon mobilization and release and their interaction to form a positive feedback loop. However realistic estimation of carbon fluxes from Arctic soils requires a proper knowledge of initial carbon density, hydrological parameters, net primary productivity, etc., for the particular region. At the same time various scenarios of climate change would be feasible to apply to force the model in order to obtain the range of possible $\mathrm{CO}_{2}$ and methane flux estimates.

\section{Acknowledgments}

The authors are grateful to Jean-Marc Barnola, Jérôme Chappellaz, and Dominique Raynaud for useful discussions, Michel Sacchettini, Marie-Christine Mieulet, and Jean-Yves Peterschmitt for technical support. D. Khvorostyanov would like to thank also Masa Kageyama and Didier Paillard for partial funding of his work (Prix Louis D. de l'Académie des Sciences 2004). 


\section{Appendix: List of equation symbols}

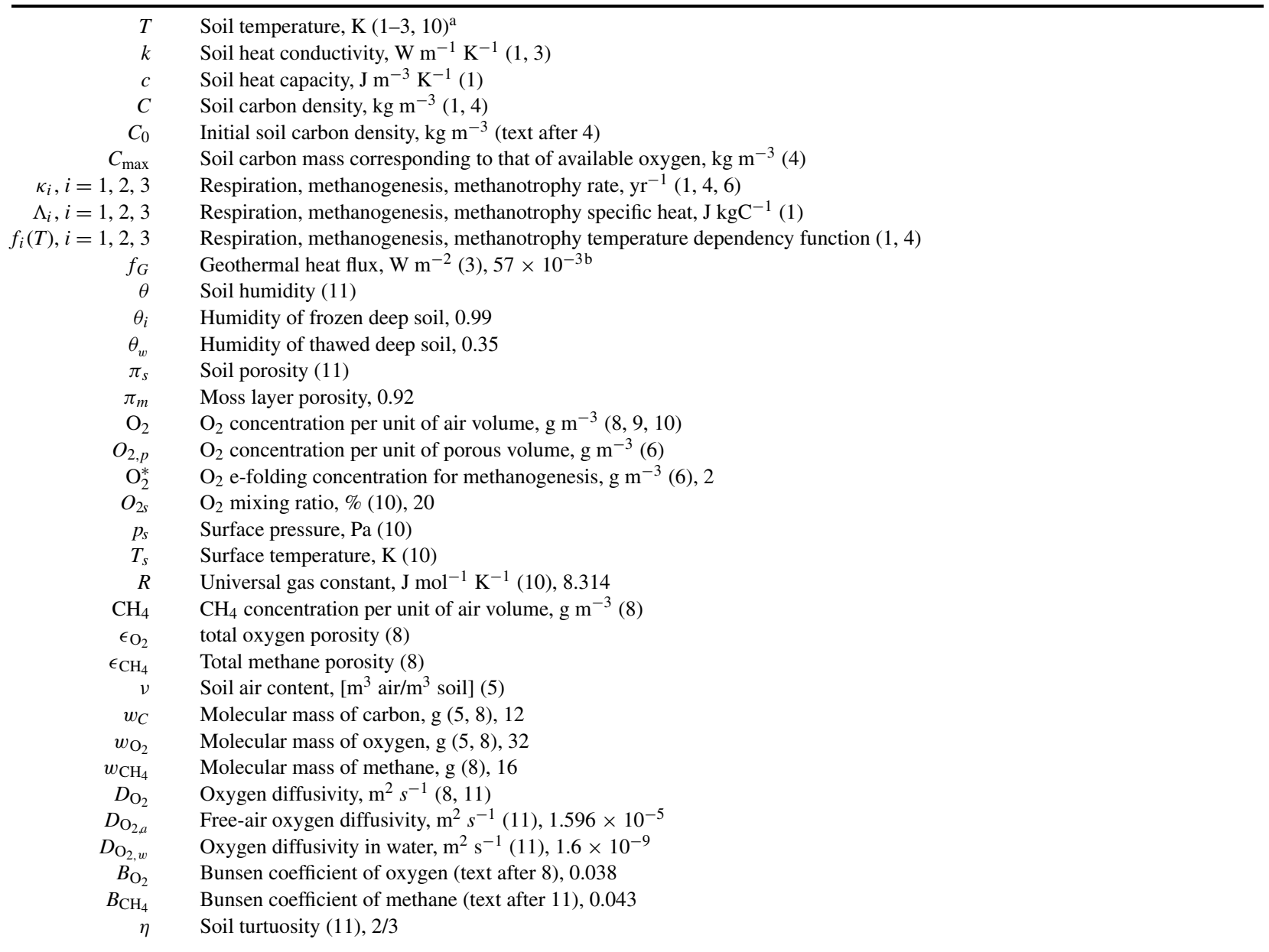

${ }^{a}$ Numbers in square brackets refer to equations in the text in which the variable is used.

${ }^{\mathrm{b}}$ These numbers show, where relevant, reference values of model parameters.

\section{References}

Andrén, O. and Paustian, K. 1987. Barley straw decomposition in the field: a comparison of models. Ecology 68, 1190-1200.

Anisimov, O. A. and Nelson, F. E. 1997. Permafrost zonation and climate change in the Northern Hemisphere: results from transient general circulation models. Clim. Change 35, 241-258.

Botch, M. S. and Kobak, K. I. 1995. Carbon pools and accumulation in peatlands of the former soviet union. Global Biogeochem. cycles $\mathbf{9}$, 37-46.

Cao, M. and Woodward, F. I. 1998. Dynamic responses of terrestrial ecosystem carbon cycling to global climate change. Nature 393, 249252.

Chuprynin, V., Zimov, S. and Molchanova, L. 2001. Modelling of thermal conditions of soils-and-grounds subject to the biological heat source. Kriosfera Zemli 6(14), 80-87.

Clein, J. S. and Schimel, J. P. 1995. Microbial activity of tundra and taiga soils at subzero temperatures. Soil Biol. Biochem. 27, 1231-1234.

Conrad, R. 1989. Control of methane production in terrestrial ecosys- tems. In: Exchange of Trace Gases Between Terrestrial Ecosystems and the Atmosphere (eds M. Andreas and D. Schimel). John Wiley \& Sons Ltd, S. Bernhard, Dahlem Konferenzen, 39-58.

Cox, P., Betts, R., Jones, C., Spall, S. and Totterdell, I. 2000. Acceleration of global warming due to carbon-cycle feedbacks in a coupled climate model. Nature 408, 184-187.

Cramer, W., Bondeau, A., Woodward, F., Prentice, I., Betts, R. and coauthors. 2001. Global response of terrestrial ecosystem structure and function to $\mathrm{CO}_{2}$ and climate change: results from six dynamic global vegetation models. Global Change Biol. 7, 357-373.

Demchenko, P. F., Eliseev, A. V. and Mokhov, I. I. 2001. Sensitivity of permafrost cover in the Northern Hemisphere to climate change. Clivar Exchanges 6, 9-11.

Dufresne, J.-L., Friedlingstein, P., Berthelot, M., Bopp, L., Ciais, P. and co-authors. 2002. On the magnitude of positive feedback between future climate change and the carbon cycle. Geophys. Res. Lett. 6(14), $1-4$.

Duval, B. and Goodwin, S. 2000. Methane production and release from two New England peatlands. Int. Microbiol. 3, 89-95. 
Fang, C., Smith, P., Moncrieff, J. B. and Smith, J. U. 2005. Similar response of labile and resistant soil organic matter pools to changes in temperature. Nature 433, 57-59.

Goulden, M. L., Wofsy, S. C., Harden, J. W., Trumbore, S. E., Crill, P. M. and co-authors. 1998. Sensitivity of boreal forest carbon balance to soil thaw. Science 279(5348), 214-217.

Hillel, D. 1980. Fundamentals of Soil Physics. Academic Press, New York.

Hodgman, C. D. ed. 1960. Handbook of Chemistry and Physics. The Chemical Rubber Publishing, Cliveland, OH.

IPCC, 1998. The Regional Impacts of Climate Change: An Assessment of Vulnerability. Cambridge University Press, Cambridge.

IPCC, 2001. Climate Change 2001: The Scientific Basis. Contribution of Working Group I to the Third Assessment Report of the Intergovernmental Panel on Climate Change. Cambridge University Press, Cambridge/New York.

Jackson, R., Canadell, J., Ehleringer, J., Mooney, H., Sala, O. and coauthors. 1996. A global analysis of root distributions for terrestrial biomes. Oecologia 108, 389-411.

Kaetterer, T., Reichstein, M., Andrén, O. and Lomander, A. 1998. Temperature dependence of organic matter decomposition: a critical review using literature data analyzed with different models. Biol Fertil Soils 27, 258-262.

Keeling, R. F., Piper, S. C. and Heimann, M. 1996. Global and hemispheric $\mathrm{CO}_{2}$ sinks deduced from changes in atmospheric $\mathrm{O}_{2}$ concentration. Nature 381, 218-221.

Khvorostyanov, D. V., Ciais, P., Krinner, G., Zimov, S. A., Corradi, C. and co-authors. 2008. Vulnerability of permafrost carbon to global warming. Part 2: Sensitivity of permafrost carbon stock to global warming. Tellus 60B, doi:10.1111/j.1600-0889.2007.003366.x.

Knorr, W., Prentice, I. C., House, J. I. and Holland, E. A. 2005. Long-term sensitivity of soil carbon turnover to warming. Nature 433, 298-301.

Koschorrek, M. and Conrad, R. 1993. Oxidation of atmospheric methane in soil: measurements in the field, in soil cores and in soil samples. Global Biogeochem. Cycles 7, 109-121.

Krinner, G., Viovy, N., de Noblet-Ducoudré, N., Ogée, J., Polcher, J. and co-authors. 2005. A dynamic global vegetation model for studies of the coupled atmosphere-biosphere system. Global Biogeochem. Cycles 19, GB1015. doi:10.1029/2003GB002199.

Lawrence, D.-M. and Slater, A. G. 2005. A projection of severe nearsurface permafrost degradation during the 21st century. Geophys. Res. Lett. 32, L24401.

Lloyd, J. and Taylor, J. A. 1994. On the temperature dependence of soil respiration. Funct. Ecol. 8, 315-323.

MacDonald, G. J. 1990. Role of methane clathrates in past and future climates. Clim. Change 16(3), 247-281.

Mack, M. C., Schuur, E. A. G., Bret-Harte, M. S., Shaver, G. R. and Chapin, F. S. 2004. Ecosystem carbon storage in arctic tundra reduced by long-term nutrient fertilization. Nature 431, 440-443.

Marreto, T. and Mason, E. 1972. Gaseous diffusion coefficients. J. Phys. Chem. Ref. Data 1(1), 3-110.

Muhs, D. R. and Bettis, E. A. III. 2003. Quaternary loess-paleosol sequences as examples of climate-driven sedimentary extremes. In Special Paper 370: Extreme depositional environments: mega end members in geologic time, volume370, pages 53-74. The Geological Society of America.

Osterkamp, T., Esch, D. and Romanovsky, V. 1998. Permafrost. In: Implications of Global Change in Alaska and the Bering Sea Region (eds
G. Weller and P. Anderson). Proc. Workshop, June 1997, University of Alaska Fairbanks, Fairbanks, Alaska, 157.

Poutou, E., Krinner, G., Genthon, C. and de Noblet-Ducoudré, N. 2004. Impact of soil freezing on future climate change. Clim. Dyn. 6(14), 621-639.

Price, S. J., Sherlock, R. R., Kelliher, F. M., McSeveny, T. M., Tate, K. R. and co-authors. 2003. Pristine New Zealand forest soil is a strong methane sink. Global Change Biol. 10, 16-26.

Ratkowsky, D. A., Olley, J., McMeekin, T. A. and Ball, A. 1982. Relationship between temperature and growth rate of bacterial cultures. $J$. Bacteriol. 149, 1-5.

Richardson, C. and Wright, D. 1984. A model for generating daily weather variables. Technical report, U.S. Dept. of Agriculture, Agric. Res. Serv.

Romanovsky, N. 1993. Osnovy Kriogeneza Litosfery. Moscow State University, Moscow.

Schlegel, H. 1992. Allgemeine Mikrobiologie. Georg Thieme Verlag, Heidelberg, Germany.

Serreze, M. C., Walsh, J. E., Chapin, F. S. III., Osterkamp, T., Dyurgerov, M. and co-authors. 2000. Observational evidence of recent change in the northern high-latitude environment. Clim. Change 46, 159-207.

Sowers, T., Bender, M., Raynaud, D. and Korotkvich, Y. 1992. $\delta^{15} \mathrm{~N}$ of $\mathrm{N}_{2}$ in air trapped in polar ice: a tracer of gas transport in the firn and a possible constraint on ice age-gas differences. 97:1568315697.

Stendel, M. and Christensen, J. H. 2002. Impact of global warming on permafrost conditions in a coupled GCM. Geophys. Res. Lett., 29(13), 10.1029/2001GLO14345.

Stolbovoi, V. and McCallum, I. 2002. CD-ROM "'Land Resources of Russia”. International Institute for Applied Systems Analysis and the Russian Academy of Science, Laxenburg, Austria.

Tans, P. P. 1998. Oxygen isotopic equilibrium between carbon dioxide and water in soils. Tellus 50B, 163-178.

Tarnocai, C. 1999. The effect of climate warming on the carbon balance of cryosols in Canada. Permafrost Periglacial Process. 10, 251263.

Waelbroeck, C., Monfray, P., Oechel, W. C., Hastings, S. and Vourlitis, G. 1997. The impact of permafrost thawing on the carbon dynamics of tundra. Geophys. Res. Lett. 24, 229-232.

Walter, B. P., Zimov, S. A., Chanton, J. P., Verbyla, D. and Chapin, F. S. 2006. Methane bubbling from Siberian thaw lakes as a positive feedback to climate warming. Nature 443, 71-75.

Walter, P. and Heimann, M. 2000. A process-based, climate-sensitive model to derive methane emissions from natural wetlands: Application to five wetland sites, sensitivity to model parameters, and climate. Global Biogeochem. Cycles 6(14), 745-765.

Wiesenburg, A. and Guinasso, N. L. Jr. 1979. Equilibrium solubilities of methane, carbon monoxide and hydrogen in water and sea water. J. Chem. Eng. Dat. 24, 356-360.

Williams, M., Eugster, W., Rastetter, E. B., Mcfadden, J. P. and Chapin, F. S. III. 2000. The controls on net ecosystem productivity along an Arctic transect: a model comparison with flux measurements. Global Change Biol. 6(s1), 116-126.

Zazula, G. D., Froese, D. G., Schweger, C. E., Mathewes, R. W., Beaudoin, A. B. and co-authors. 2003. Ice-age steppe vegetation in east beringia. Nature 423, 603 .

Zhuang, Q., McGuire, A. D., Melillo, J. M., Clein, J. S., Dargaville, R. J. and co-authors. 2003. Carbon cycling in extratropical ecosytems of 
the northern hemisphere during the 20th century: a modelling analysis of the influences of soil thermal dynamics. Tellus 55B, 751776.

Zimov, S. A. 2005. Pleistocene Park: Return of the Mammoth's Ecosystem. Science 308, 796-798.

Zimov, S. A., Davydov, S., Zimova, G., Davydova, A. I., Zimov, N. S. and co-authors. 2004. The role of the permafrost reservoir in the global carbon budget. In: AGU Abstracts, B31A-0204. American Geophysical Union.

Zimov, S. A., Schuur, E. A. G. and Chapin, F. S. III. 2006. Permafrost and the Global Carbon Budget. Science 312, 1612-1613.

Zimov, S. A., Voropaev, Y. V., Semiletov, I. P., Davidov, S. P., Prosiannikov, S. F. and co-authors. 1997. North Siberian lakes: a methane source fueled by pleistocene carbon. Science 277, 800-802. 